\title{
Why medical and nutritional experts can't seem to agree
}

\section{Opinion}

Science is tricky. Much depends on 'peer reviewed' studies. That just means a consensus and that consensus is, more often than not, WRONG. Over time science Learns new things, old theories are discredited and new theories proposed. There really are few undisputed FACTS in science; it is an evolving quest for knowledge!

As someone focused on Health \& Wellness, I constantly review current and evolving science as it relates to Nutrition, Diet and FOOD. As a pretty strict, Plant Based Nutrition advocate, I am constantly looking, reviewing and searching out the best available sources for good nutritional options. Not only to fight and reverse disease but to seek out Delicious Cuisine!

My focus is self-serving to a large extent. I've been strictly Plant Based (vegan) for over 8 years now. That is three-five years beyond the lifespan I was given by the best Cancer Oncology Experts! Yea, go figure. ALL I did was change my Lifestyle; no treatments, protocols, surgeries or drugs. So, I am pretty invested in this Lifestyle Approach as it continues (at $70+$ years of age) to provide me with excellent health, energy and vitality.

\section{The experts can't agree}

So Why in HELL can't even the experts, in this and other fields, ever agree or at least come to a consensus? Because the human body is complex beyond our understanding. The genetic variations are almost infinite; well beyond any computer predictive algorithm. The environments on our Planet are so very different as are the available localized food supplies. I don't think ANY SINGLE diet or nutritional base can be advocated for everyone.

The Health Industry today, focuses on Treatment, but NOT PREVENTION. Lots of reasons I suppose. Ignorance is one, money is a driving force; only sick people generate revenue and many are just treated to death. The Healthcare Industry is so focused on treatment they fail to address prevention.

Leading Experts in the Nutrition Field who mostly agree on foundation of Plant Based Foods still can't agree:
i. Dr. John McDougal - Focuses on a Starch Diet
ii. Dr. Caldwell Esselstyn - NO Oil
iii. Dr. T. Collin Campbell - Plant Based with NO Casein
iv. Dr. Joel Furhman - Micronutrient Rich Diet
v. Dr. Neil Barnard - Save the animals with a vegan diet
vi. Dr. Andrew Saul - Megavitamin Doctor
vii. Dr. Dean Ornish - Low fat plant based diet

viii. Dr. Michael Greger - How Not to Die (my personal favourite)

All these noted and famous Physicians ALL agree on the basic

\author{
Volume 6 Issue 3 - 2017
}

\author{
Skip Stein \\ Plant Based Lifestyle Consultant, Whole Foods 4 Healthy Living, \\ USA
}

Correspondence: Skip Stein, Plant Based Lifestyle Consultant, Chief Operating Officer,Whole Foods 4 Healthy Living, Orlando, Florida, USA, Tel 4076836816,

Email skipstein@wholefoods4healthyliving.com

Received: March 03, 2017| Published: April 19, 2017

approach of a Plant Based diet, consisting of mostly vegetables, nuts, seeds and fruit. However, they also ALL disagree on any single dietary approach. They quote different studies, experiential evidence, historical/archeological and other evidentiary documents to support their approach. Of these, my favourite is Dr. Michael Greger because he expresses little personal opinion, just presents the current science in peer reviewed studies and experiments.

\section{So, what the heck is a person to do?}

Dr. Joel Furhman has said that "Plant Based" means PREDOMINANTLY eating plants: vegetables, legumes, nuts, seeds and fruit. There IS allowance for other foodstuffs and for some that may mean continued consumption of some meat/fish or other animal based foods.

I continue to fervently believe that a strictly Plant Based Diet and Lifestyle is the best approach for ME; it may not suite everyone. I can discuss a plethora of reasons for my choice and why I recommend this approach. Amongst the many supportive reasons, the predominate one is supportive of the natural immune system. The cultivation of plant based digestive gut bacteria has proven to be beneficial for so many; unpolluted by animal food digestive bacteria. It just enhances the basic immune system so you seldom, if ever, get sick.

This helps PREVENT lifestyle diseases of cancer, heart disease, diabetes and more. The immune system is critical to maintaining a healthy body, mind and spirit. Sick people do not do well with almost anything. Mental focus, energy, creativity etc.; if you are sick you just can't focus on much of anything besides getting well again. With a strong immune system, you generally never have to worry about getting sick!

As with most things in life, it is a matter of Choice. You can choose to be well or sick. Yes, there are outside forces, contaminations, bacterial and viral nasties that attack, but even if you do get a cold or touch of the flu; in general, it won't be as bad and you will recover quicker. 
So, what to do? I would suggest you try, yes at least TRY a Plant Based Diet for 30 days. It really can't hurt and you will be amazed, especially if you have been eating the standard American diet, how great you will begin to feel. The food/meal options are beyond numerous and most are absolutely delicious. We usually see major improvement in energy, complexion, weight and blood work in WEEKS not months. It may amaze you!

If, for whatever reasons, this is just not for you; at least you will have tried. In our experience, those who revert to a standard American diet, loose that 'edge' and admit that they just don't feel as well as they did. Lots of reasons, some more valid than others in my opinion.

It the end, it is Your Life, Your Choice. I hope you will at least TRY a Plant Based approach to test it and fell the change to your body, mind and spirit. We are here to help. As a matter of fact, my lovely wife, Chef Nancy just published her first book: "Restoring American's Health Simple Steps to a Plant Based Lifestyle". It is available in eBook and paperback versions. Chef Nancy also has over 20,000 recipes on her Pinterest site to enjoy. See below for links.

\section{Remember, "Your health is your wealth"}

Skip Stein is a Lifestyle Counsellor focusing on a Plant Based
Approach. His wife, Chef Nancy, is certified in Plant Based Nutrition and provides dietary and cooking classes. Together they work together to Restore America's Health!

Restoring America's Health $\sim$ Simple Steps to a Plant Based Lifestyle:

https://www.createspace.com/6906099

Chef Nancy on Interest: https://www.pinterest.com/Gramstein/

Whole Foods 4 Healthy Living: http://www. wholefoods4healthyliving.com/

Plant Based Lifestyle: http://plantbased-lifestyle.com/

\section{Acknowledgements}

None.

\section{Conflict of interest}

Author declares that there is no conflict of interest. 